\title{
The Influencing Factors on the Effectiveness of Foundation Training Programs: A Case Study of the Health Cadre Service in Bangladesh
}

\author{
Mohammad Ziaur Rahman \\ Master of Management (By Research) \\ Faculty of Business and Accountancy \\ University Selangor, Malaysia \\ E-mail: ziaurcu97@gmail.com \\ Mokana A/P Muthu Kumarasamy PhD \\ Lecturer \\ Faculty of Business and Accountancy \\ University Selangor, Malaysia \\ E-mail: mokana@unisel.edu.my \\ Abul Bashar Bhuiyan $P h D$ \\ Associate Professor \\ Faculty of Business and Accountancy \\ University Selangor, Malaysia \\ E-mail: bashariuk@gmail.com
}

\begin{abstract}
The research has been conducted to understand the training effectiveness where health professional participates for training who work under the Bangladesh Government. The research used the Kirkpatrick model. The paper has collected data form, 323 participants. The research measured the training effectiveness using survey questions. The multiple regression techniques have used to conduct analysis of the collected data. The findings of the research revealed that the training effectiveness has been affected significant positively by training motivation, trainer qualification, and training design. Moreover, the training environment does not have significant role on the impacting of the training effectiveness respectively. The study has specific recommendations based on the above findings as the bench mark to improve the effectiveness training in Bangladesh and the regions.
\end{abstract}

Keywords: Influencing Factors, Foundation Training Programs, Health Cadre Service, Bangladesh.

\section{Introduction}

According to the Public Administration Training Policy-2003, the government officials who are Class-I have to get foundation training as compulsory. For this reason, the entire Cadre who works under Bangladesh has to participate in the foundational course. The training has a part where the Cadre is taught on the topic of responsibility, accountability. The Government of Bangladesh is concerned about helping the Cadre to build skills and knowledge where the foundational training and development helps the participants. Health care officers also get foundation training. But the question comes whether these training bringing any fruit for the participants.

The training has a positive relation with creating an effective workforce (Alvarez, Salas, \& Garofano, 2004). But organizations are not efficient to evaluate the existing training facilities. This makes the organization lose money and the employees do not get sufficiently trained (Kirkpatrick \& Kirkpatrick, 2015). The purpose of the evaluation is to understand the training and its capacity to teach the participants. The organization gets benefited by understating and making changes after evaluating the existing Training programs where the organization get better-trained employees and cost related to such training gets optimized (Bates, 2004). The government is spending to train the cadre and if the cadre is not able to transfer knowledge and skills form these programs then the policymaker has to explore alternatives to improve the training programs.

The real question comes does the effort of the government and the time of the Health cadre are being utilized at full extent. The reason is that health cadre is already medical qualified. The training programs should make them conduct their work easier otherwise they are wasting their time in the workplace. The government, on the other hand, is spending the taxpayer's 
money to train up the health cadre to provide the people especially the rural people to have the best possible health care possible through these already qualified health cadres. But measuring the effectiveness of the training program has to address certain areas. The measuring of what the research has addressed and also address which areas to be focused to understand if the training program is effective requires to understand how others measure the effectiveness of training or education and what areas they focus on the success of those training.

The research has found that Kirkpatrick's suggestion to measure the training program has been used for quite a time. The reason for success to this is due to the fact it focuses on a topic such as reaction, learning, behaviour, and result (Kirkpatrick \& Kirkpatrick, 2015). There is other research and models have focused on factors that the training motivation, trainer qualification, training environment, and so on have an impact on the research (Alvarez et al., 2004; Bates, 2004; Gopa B Choudhury \& Vedna Sharma, 2019). A good training program should have these criteria's. The training programs conducted by the government/ funded by the government should be addressed of these variables to understand the impact of the training on the trainee and also understand which factors to focus to improve the training programs.

The research will be conducted to explore the effectiveness of the programs that are offered to the health cadre. The purpose is to understand which elements are vital to measuring the impact of the research. The research will try to understand which areas the training are doing well and which areas should be focused by the trainers to provide the cadre better training to utilize the health cadre's capacity and funding to these programs.

\section{Background of the Study}

The training is done for gaining skills as well as preventing obsolescence due to lack of skills. The training is costly and is challenging in some cases to implement them in real life situation. The reason is not all facilities are equipped to conduct the same level of the training and not all facilities have the same level of skilled teachers. The quality of the training facility depends on the available learning environment. The performance quality, behaviour, attitude toward transformation, and the value system that the employees are exposed are affected by the learning environment in the training facility.

The Human Resource Development considers the people as a source of catalyst that drives the development. The people want to sharpen their skills, capacity, and competencies where these people are driven by their desire to achieve personal goals and along the way the organizational goals. For national context, the groups within the country are developed by the individuals for achieving self-confidence, self-reliance and self-support. The role of education in this context is vital but the training facilities are essential in this context due to the training provides the individuals with the competencies for the required work.

Public Administration Training Policy-2003 states that foundation training is mandatory for government officials who are classified as class-I. The Cadre officers of Bangladesh government officials have to go through training courses that are foundational in nature. The purpose of such training is that the cadre officer will have enhanced knowledge and this will be used as a platform to every cadre officers (GoB, 2003).

The study will focus on these foundation courses and what factors influence these foundation courses. The taught Couse in the foundation course focuses on personality building, creative stimulation, and leadership development to the target trainees. The target of this course is to provide the cadre to be familiarized with enhanced dimension where they get ideas about the development of the country with a socio-economic context. The purpose of such introduction to the socio-economic context is to provide the administrators to be more competent in their duties.

The study will focus on identifying the influencing factors that have an effect on the foundation training programs which is conducted by NAPD focusing on the Health Cadre officers of Bangladesh Government. The purpose of this study will identify the influencing factors that can help or hinder the teaching of the foundation training program. The benefit of identifying and understanding of such factors will help the reader of this study which factors are influential, which factors are helping the trainees, and which factors are hindering the trainees.

The reason to understand such matter is vital due to the fact the trained officials serve in different parts of the country. The areas include remote areas which are not directly connected with city areas. The study will try to critically evaluate the factors because the training of the cadre regularly might not be possible due to serving the local need in different parts of the country. If the program has some hindering factors that have to be addressed and stabilized to get better benefit. The study will be beneficially for the policymakers and the academics alike. The policymakers will get ideas which factors works in training the Government Cadres and which factors to be looking out for in such training. The academics will be able to get ideas on the factors that influence such training and they will be able to design better courses with keeping this study in mind.

\section{Literature Review}

Training is done for enhancing the skills of the trained personnel. Healthcare is playing a vital role in any country. The NAPD provides training for the Health Cadre in Bangladesh. The purpose of the training is to provide the training that will enable them to work in the remote areas in many parts of the country where every citizen of Bangladesh will be able to get the necessary 
health care. Further, training is also a chance to become social and share ideas. This section of the research will focus on the training and development related literature review that is available.

\section{I Training and Development}

The training is done for developing purpose where the individuals get the chance to improve, enhance, and update the necessary skills, knowledge, and abilities to perform the jobs in professional life. The training helps the individuals to face the external environment where the factors are unknowns. The benefit of training provides the trained officials to work in the environment and provide quality solutions or treatment that helps the patients (Niazi, 20I I).

The term training refers to enabling the employees with traditional or newer methods, techniques, or use instruments that help them to translate knowledge, information, and skills to be used within the organization to achieve the organizational goal. The training is usually done for facing the current or future problems faced in the workplace (Gherardi, I999). The organizational goal is to achieve some goals. The training helps the organization to make its employees be capable to achieve those goals. In the literature about training and development, it has been found that training and development have a correlation with improved organizational goals. But the training has to be designed on the basis which will serve the organization to achieve its goals (Niazi, 20II). There are arguments about why the development has to be achieved. Some writers argue that the training has to be the basis for improving the human capital of a country. But those research are mainly done the basis of the civil service (Gherardi, I999).

\subsection{Human Resource Management's Role in Training and Development}

The human resource management is mainly focused on the training facilities along with recruiting activities. The purpose of the HRM is to enable and foster the employees of the organization. The different institution has a different name for the HRM. But whatever the name is called this institution focus on enhancing the skills, ability, and knowledge of the employees. The need for training is a necessary factor of the business this has been on the mind of the employers due to the challenges faced in the real world. The external environment becomes more challenging and the competition has become fierce. In a business context, many businesses are found to invest millions of dollar to educate the workforce.

The expenditure is done to meet the rapid challenges that are sometimes found to be unique and requires a special need for training. The HR department, for this reason, is more cautious in making the job design. They have to understand the job requirement and how the job requirement will be changed in the future. The understating of the job is essential to understand what type of training programs will be needed (Rafiq, 2015).

There is a researcher that identified the training and development as the contributing factor for both the organization and the employee's development. Origination's main focus is the organizational achievement of goals. But the training helps the business to be relevant in the market place. The investment in the employees helps the employees to shine in their career (Rafiq, 2015). For the civil services, the training is more about creating a helpful situation for the people in general.

\subsection{Modern Meaning of the Training}

The training referred to as the simple meanest that helps to learn something new through practices. The training is a vital building block for human capacity development. The training is also an input for the development in socio-economic development (Atiyyah, 199I). The training is also a personal journey where each person gets to update, upgrade their knowledge, skill, analytical framework which are essential to conducting the activities of the organization. The organization level training is a procedure that is formal in nature. The training changes the employees in a behavioural aspect. The employees get stronger mentally to face organizational challenges(Bolman \& Deal, I99I).

The training facilities now focus on the leadership aspect. The leadership is a group activity where the leader leads his group to archive organizational goals where his personal skill motivates the group to lead to achieving those goals (Carter, Seely, Dagosta, DeChurch, \& Zaccaro, 2015). In the current situation, the civil service requires leaders in different parts of the country. The purpose is to enable the civil officers to archive organizational goals by serving the community where they are posted (Carter et al., 2015).

The organization consists of people. These people create social groups. The target of the organization is to lead these social groups to achieve organizational goals. In most cases, the people recruited are from different areas, culture, their norms, value belief are somewhat different. Organization's management has to understand such differences. The need to understand such a difference is vital to design the training facilities. The training design has to address that the people working within the organization has to respect other individual's culture, a belief which is not conflicting within the country's accepted norms and belief in general. But within a change of times, there have to be updated.

The reason is the job requirement and culture changes with time. Once there not many women in the workforce but with a change of time, the workforce sees that there are a lot of women in the workforce (Ahmed, 2016). The need for higher skill in the higher position along with the need for new skills to conduct jobs has been building up due to changes in technologies. The higher position is now needed knowledge of leadership and also needs to train the employees or subordinates 
to better perform to achieve organizational goals. The changing time has provided a newer need for technical knowledge. This has created the need for creating training programs that help the employees to be relevant in the workplace to better perform the jobs. The employees with time gain experience with time. The value of these employees is high. But with time these employees need some new technological or legal knowledge that can be achieved by training (Govil \& Usha, 20I4).

Govil and Usha (2014) described that the organization face problems due to the challenges that the organization face forms the external environment. The only way to face these challenges and keeping themselves relevant is through training for gaining new knowledge and improving skills. The training is an approach that is systematic and the purpose of such training is adding skills and developing knowledge within a short period where the same skill-building would take more time from practical experiences. But effective training depends on the design of the training. Training design has to be done keeping the job requirement and the capacity of the employees where the training is supposed to improve the performance, productivity and also develops the ability to learn (Govil \& Usha, 20I4).

The economic factors have to be addressed in the training (Newland, 1976). Training is essential for developing employees. But these trainings are not cheap to conduct. The failure of such training costs the organization. The Civil services are for the people of a country. The loss from any training where the employees do not learn anything will cost the taxpayer's money. The purpose of the training is to improve the services that are worth the taxpayer's money or saves taxpayers' money (Newland, 1976).

\subsection{Empirical Models for Training Evaluation}

For evaluation of the training programs, there are several evaluation models. Systems approach or input, process, output (IPO) model, Brinkerhoff s six-stage evaluation model., Context, input, process, and product (CIPP) model, Context, input, reaction, and outcome (CIRO) model, Kaufman and Keller's and Phillips' five levels of evaluation, Swanson's performance improvement evaluation model, Holton's three-level HRD evaluation and research model are among popular evaluation models.

\subsection{Framework of the Study}

The research will consider Kirkpatrick's four-level evaluation as the main model to evaluate the effectiveness of the training programs that are offered by the NAPD. The training effectiveness here has four measurements these are reaction, learning, behaviour, and result. These are all dependent variables. Because these variables are affected by influencing factors such as training motivation, trainer qualification, training design, and working environment (Paull et al., 2016).

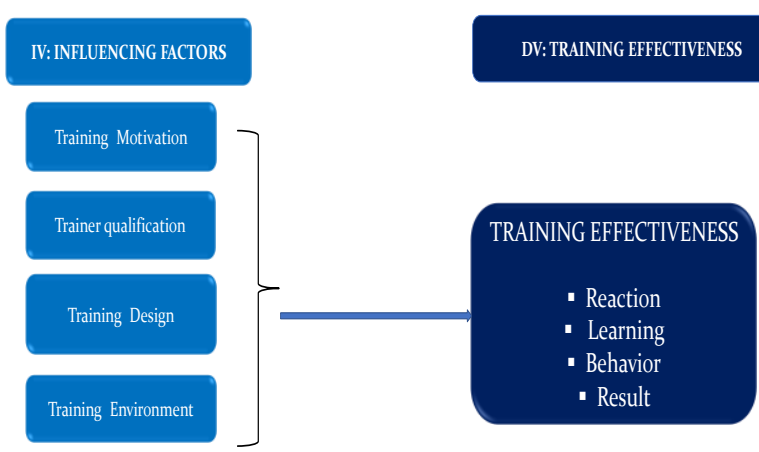

Figure I. Study Framework

\section{Research Methodology}

The research will use a survey method to collect data. The study used descriptive statistics and econometric model used in the research to be explored relationship between and Independent and Dependent variables. ANOVA, T-test, Correlations and frequency test will be used in this research on the survey data. There will be used multiple regression to identify the relationship between depended and independent data. The interpretation will be made from the analysis. The interpretation will provide the readers about what the participant's response related to the research.

\section{Analysis and Finding}

\section{I Descriptive Statistics}

The descriptive statistics has explored to understand and describe the collected data. The purpose here is to understand the data and help the reader to further understand the characteristics form analysis that will help in the later sections. 
The data shows that the mean value by age is 33.5I. The minimum age of the participants is 28 years. The maximum age of the participants is 47 years.

Table-I. Descriptive Statistics (Author's creation, 2019)

\begin{tabular}{|c|c|c|c|c|c|}
\hline \multicolumn{6}{|l|}{ Descriptive Statistics } \\
\hline & $\mathrm{N}$ & 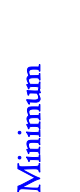 & 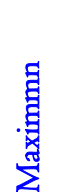 & $\sum_{\Sigma}^{\tilde{\varpi}}$ & 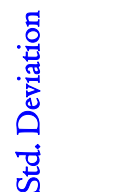 \\
\hline Age & 323 & 28.0 & 47.0 & 33.511 & 2.6649 \\
\hline Sex & 323 & 1.0 & 2.0 & 1.430 & .4959 \\
\hline Training_Effective & 323 & 1.00 & 3.41 & 1.9420 & .39830 \\
\hline Reaction & 323 & 1.00 & 4.00 & 2.0093 & .52306 \\
\hline Learning & 323 & 1.00 & 3.67 & 1.8013 & .42544 \\
\hline Behavior & 323 & 1.00 & 3.75 & 1.9110 & .50542 \\
\hline Result & 323 & 1.00 & 4.20 & 2.0464 & .50360 \\
\hline Training_motivatoin & 323 & 1.00 & 4.33 & 1.9195 & .53425 \\
\hline trainer_qulific & 323 & 1.00 & 4.00 & 2.0193 & .49651 \\
\hline training_design & 323 & 1.00 & 4.43 & 2.2136 & .49747 \\
\hline training_env & 323 & 1.00 & 3.71 & 2.2234 & .54062 \\
\hline Valid N (listwise) & 323 & & & & \\
\hline
\end{tabular}

A separate analysis has been conducted to understand the variable wise average response. The purpose to show these activities in this manner to provide users with ease to how individual questions helped the variables to be formed. The average calculation has been done in this section using MS Excel and the graph was created with that program.

\subsection{Further Analysis of the Responses for Questions}

The reaction measurement is part of the training effectiveness. The first four questions have asked to measure the reaction of the respondent about the training program that they have participated in. The questions included how the training met the expectation of the participants, the overall course benefit to the participants, the learnt materials, and did the participants used the learned material in the professional life. The average response in this section is 2.00 or agreed on the questions for this section.

Question 5 to 10 is focused on learning from the training. The purpose is to understand how the course helped the participants to understand the training where they learned from the course and how the learning helped them in professional life. The average response in "learning" is I.80 or the participant agreed on learning from the course.

Question II to I4 focused on the behaviour where the training changed the behavior of the participants about the trained topic. The behavior here referred to as the mental change in conducting future professional works. The average score is I.9I or the participants agrees that the training helped change their behavior.

Question I5 to 19 focused on the result or what the participant acquired from the training program. The question included how they view the knowledge helped them to communicate with a subordinate, improve skills, problem-solving, personal productivities and how the official operation cost decreased from in day-to-day operation. The average response is 2.04 or agreed by the participants that the training has results.

The question I-I9 measured reaction, learning, behavior, and result. These items are components of the Kirkpatrick model to evaluate training effectiveness. The items described has been found to be helpful to measure the turning effectiveness of training programs(Bates, 2004; Kirkpatrick \& Kirkpatrick, 20I5). The average of the all compete is I.94. Which means the participant on average agrees that the training program has effectiveness in training the participants.

Training motivation asks if the new skills motivated the participated, if the participants feel motivated to apply their knowledge and if their presentation skills have improved. Question 20 to 22 addressed these questions. The average response is that the participants aggress that the training motivation exists or I.9I.

The research tries to understand if the trainer's qualification has any impact on training effectiveness. For this reason, question 23 to 30 has asked the users to answer how the trainer helped the participants to learn technical and soft skill throughout the training period. The participants on average choose 2.0I or agreed on the trainer's qualification. 
Training design is another vital part due to the effective training design helps the participants to learn fast and effectively. The research questionnaire focused on this variable form question $3 \mathrm{I}$ to 37 . The participants agree on average 2.2I that the training design is satisfactory for the subject program.

The training environment is where the participants learn and participate in training. The effective training environment helps the participants to learn and practice their knowledge before applying those learning in professional life. The last eight questions focused on the training environment. The average response is the participants agree that the training environment existed where the training was conducted. Question number 38 to 44 has explored this variable. The average response in this section is 2.22 .

\subsection{Regression}

The regression has been done for this paper. The purpose has been to understand which of the independent variables have more impact on the dependent variable.

\begin{tabular}{ccccc}
\hline \multicolumn{5}{c}{} \\
\hline Model & $\mathrm{R}$ & $\mathrm{R}$ Square & Adjusted R Square & Std. Error of the Estimate \\
\hline $\mathrm{I}$ & $.752^{\mathrm{a}}$ & .565 & .559 & .26440 \\
\hline a. Predictors: & (Constant), training_env, Training_motivatoin, training_design, trainer_qulific \\
\hline
\end{tabular}

Table 2. ANOVA (Author's creation, 2019)

\begin{tabular}{|c|c|c|c|c|c|c|}
\hline \multicolumn{7}{|c|}{$\mathrm{ANOVA}^{\mathrm{a}}$} \\
\hline Model & & Sum of Squares & $\mathrm{df}$ & Mean Square & $\mathrm{F}$ & Sig. \\
\hline \multirow[t]{3}{*}{$\mathrm{I}$} & Regression & 28.853 & 4 & 7.213 & 103.185 & $.000^{b}$ \\
\hline & Residual & 22.230 & 318 & .070 & & \\
\hline & Total & 51.083 & 322 & & & \\
\hline \multicolumn{7}{|c|}{ a. Dependent Variable: Training_Effective } \\
\hline \multicolumn{7}{|c|}{ b. Predictors: (Constant), training_env, Training_motivatoin, training_design, trainer_qulific } \\
\hline
\end{tabular}

The model has found to have Adjusted R square to be .559 and observed R square to be .565 . This shows that the dependent variable and the independent variables have good relationship. The result shows that almost $56 \%$ the result on dependent variable by the independent variables can be explainable in this study. In the ANOVA table, F test has been done for the model. The result has found that the p-value(significance level) is .000 which is below .05 . This result shows that the dependent variable is related with all the individual independent variables.

Table 3. Regression (Author's creation, 2019)

\begin{tabular}{|c|c|c|c|c|c|c|}
\hline \multicolumn{7}{|c|}{ Coefficients $^{a}$} \\
\hline \multirow{2}{*}{\multicolumn{2}{|c|}{ Model }} & \multicolumn{2}{|c|}{ Unstandardized Coefficients } & Standardized & \multirow[t]{2}{*}{$\mathrm{t}$} & \multirow[t]{2}{*}{ Sig. } \\
\hline & & B & Std. Error & Beta & & \\
\hline \multirow[t]{5}{*}{$\mathrm{I}$} & (Constant) & .519 & .075 & & 6.905 & .000 \\
\hline & Training_motivatoin & .193 & .035 & .259 & 5.542 & .000 \\
\hline & trainer_qulific & .259 & .046 & .323 & 5.650 & .000 \\
\hline & training_design & .214 & .045 & .267 & 4.729 & .000 \\
\hline & training_env & .024 & .035 & .033 & .699 & .485 \\
\hline
\end{tabular}

Training_Effective $=B_{0}+$ Training_motivatoin + trainer_qulific + training_design + training_env

$=.519+.193$ Training_motivatoin +.259 trainer_qulific +.214 training_design +.024 training_env 
From the equation above, the result has been acquired using the SPSS software. The results indicate when all other variables are constant the training effectiveness will impact by .519. When all other variables are constant any increase in training motivation will increase the training effectiveness by .I93 in response. For training qualification's per increase will contribute .259 increase in the respondent's response where other variables are constant.

The training design variable increase will have $0.2 \mathrm{I} 4$ increases in the training effectiveness per increase to training design where other variables are constant. Finally, when other variables are constant, any increase in the training environment will cause an increase in the training effectiveness by .024 per increase.

It should be noted that form the SPSS analysis, only training environment has had significance level of .485 which is above .05 which means that we can reject that the training environment will have any impact on the training effectiveness. Other variables have significance .00 which is below the .05 . This indicates that the training motivation, training qualification, and training environment have a significant impact. From the research, we reject the null hypothesis for training motivation, training qualification, and training environment has no impact on the training effectiveness and accept that these variables have an impact on the training effectiveness. But on the other hand, the research fails to reject that the training environment has no impact on training effectiveness.

\section{Conclusion}

NAPD provides training to the Health Cadre officer who serves in a different region of Bangladesh for improving the people in an urban and rural area of Bangladesh (Kashem, 2019). The target is to make the Cadre capable of doing their work and prevent them from becoming obsolescence due to lack of skills. The cost of this training is provided by the Bangladesh Government (napd.gov.bd, 2019). Bangladesh government officials have to go through a foundational training course that helps them to build necessary skills and communicate with another cadre (GoB, 2003). But the main question here is are these courses effective enough and does the training play a vital role in the lives of the Cadre. This study focused on the elements that help a training program effective and efficient for the cadre that helps them become competent in the workplace and also become competent in the future. The research has focused on training effectiveness and has divided the elements that can be found in most training programs. These elements include training motivation, trainer qualification, training design, and training environment. These topics have been explored in this research to understand how the participants interpret them.

The training programs have got more momentum due to the establishment of the HRM in the organization and who understood that by training the employees, the employees become capable to face the current problem and also the risk of these employees obsolete becomes reduced. But for this, the department which handles human resource has to be capable and also have knowledge about the jobs and its requirement for training (Rafiq, 2015).

Training effectiveness depends on the goals that the organization wants to achieve. Because the goal of the training is the concrete matric that enables us to understand what the trainee will learn and evaluation of their work is where the trainer can say if the trainee learned what the trainee intended to learn (Sahakiants, 2015). Modern models of evaluation now try to evaluate at each level of the training. This ensures what the participants are learning but also making the participants evaluate what they are learning at each level. This testing at each level helps the trainers to take control measure when possible. Eqvet-Us is one such model (Moldovan, 2016). The Kirkpatrick model has been one of the widely used models and from which many other models have been developed. This model has been used due to its simplest design to capture the training effectiveness. But the model is not without criticism. The criticism arises due to the interpretation of the variables. Not all agree on how the participants react to the deferent variables (Kirkpatrick \& Kirkpatrick, 2015; Paull et al., 2016).

The criticism of the Kirkpatrick has given rise to another popular model such as IP, Brinkerhoffs six-stage evaluation model, CIPP, CIRO, Phillips' five-level evaluation model. Because of the different need and nature of training, not one training has been able to be the single solution to evaluate the training effectiveness. Though most of the mentioned model is widely used. But they have a significant influence from the Kirkpatrick model (Moldovan, 2016).

The research has used quantitative data. The research has developed a hypothesis. The model captured the reaction of the Health Cadre, what they have learned from the training, how their behaviour changed in the workplace, and how the training is helping the government achieve their goal in the health care (Smidt et al., 2009). The main variables of this paper are training effectiveness, training motivation, training design, trainer qualification, and training environment. The training effectiven ess has four variables reaction, learning, behaviour, results.

The data collection has found that the total population of the subject training is I I80. Form which 323 participants have provided their response for this paper. The data collection has been done through Google Form. The ethical issues have been informed to the participants. The research has collected data with direct consent from the participants.

The majority of the participants are male where the $57 \%$ are male and the remaining $43 \%$ are female. The most participant's age is between 30 to 36 years old. The mean age is $33.5 \mathrm{I}$ years. The participants participated in the survey using survey questions. The survey questions had 44 questions that covered the survey. The reaction variable had questions from I to 4 which have an average response of 2.00. The learning variable has been counted with questions from 5 to I0. The average response is I.80. The behaviour response has an average response of I.9I. This variable has been counted using questions from 
II to I4. Result variable has been counted using question I5 to I9. The average is 2.04. Training effectiveness has been calculated using the previous four variables. The average of this variable is I.94. Training motivation has been conducted using question number 20 to 22 . The average response is $1.9 \mathrm{I}$. The trainer qualification has been determined using 23 to 30 questions. The average response is 2.0I. Training design has question number 3I to 37 . The average response is $2.2 \mathrm{I}$. Training environment has been calculated using question number 38 to 44 . The average response is 2.22 .

A regression has been conducted using the collected data. The response found that the value of beta zero is .5I9 meaning when no change occurring in other values, the participant's response will change by .5I9 points. The training motivation, trainer qualification, and training design will impact the training effectiveness when only these variables are focused and other variables are constant by .193, .259, .214, and .024. These variables have a significant influence on these items. The training environment has no significant impact on training effectiveness.

The research has found that training effectiveness has an impact on training motivation, trainer qualification, and training design. The finding indicates that the Health Cadre will have better training when these items are present. Further, the improvement of these variables will ensure more training effectiveness. Though the training environment has no direct impact on training effectiveness, this factor should not be ignored.

\section{Recommendation}

The recommendation for this research is provided below:

- The training effectiveness relies on training motivation, trainer quality, training design in the BCS health cadre training. Though the training environment does not have significance in the training effectiveness, this factor should not be ignored nevertheless.

- Training motivation should focus on providing the doctors/health professionals to be motivated at work and also motivate the patient during their treatment.

- The training facility should include a mandatory evacuation of the training. This will allow the researcher to get more data and also the trainers will be able to use a different metric to measure the training effectiveness. From this type of evaluation, the trainers can also be able to understand where the trainee gets a hard time and improve the training.

- Other models should be used to evaluate the training effectiveness to understand and compare the training effectiveness and improve the training facility for better.

\section{References}

Alvarez, K., Salas, E., \& Garofano, C. M. (2004). An Integrated Model of Training Evaluation and Effectiveness. Human Resource Development Review, 3(4), 385-4I6. https://doi.org/I0.I I77/I534484304270820

Aziz, S., Mahmood, M., \& Rehman, Z. (2018). Implementation of CIPP Model for Quality Evaluation at School Level: A Case Study. Journal of Education and Educational Development, 5(I), I89-206. https://doi.org/I0.22555/joeed.v5iI.I553

Bates, R. (2004). A critical analysis of evaluation practice: the Kirkpatrick model and the principle of beneficence. Evaluation and Program Planning, 27(3), 34I-347.

Carter, D. R., Seely, P. W., Dagosta, J., DeChurch, L. A., \& Zaccaro, S. J. (2015). Leadership for Global Virtual Teams: Facilitating Teamwork Processes. In J. L. Wildman \& R. L. Griffith (Eds.), Leading Global Teams (pp. 225-252). https://doi.org/I0.I007/978-I-4939-2050-I_I0

Chen, C.-Y., Chang, H., Hsu, W.-C., \& Sheen, G.-J. (2017). Learning, behaviour and reaction framework: a model for training raters to improve assessment quality. Assessment \& Evaluation in Higher Education, 42(5), 705-723. https://doi.org/I0.I080/02602938.2016.1180663

Gopa B Choudhury, \& Vedna Sharma. (2019). Review and comparison of various training effectiveness evaluation models for R \& D Organization performance. PM World Journal, VIII(II). Retrieved from https://pmworldlibrary.net/wpcontent/uploads/2019/02/pmwj79-Feb2019-Choudhury-Sharma-comparison-of-training-effectiveness-models-forrd.pdf

Govil, S. K., \& Usha, K. (20I4). The Importance of Training in an Organization. Advances in Management, 7(I), 44.

Jones, B., Hopkins, G., Wherry, S.-A., Lueck, C. J., Das, C. P., \& Dugdale, P. (2016). Evaluation of a Regional Australian Nurse-Led Parkinson's Service Using the Context, Input, Process, and Product Evaluation Model. Clinical Nurse Specialist, 30(5), 264. https://doi.org/I0.I097/NUR.0000000000000232

Kirkpatrick, J. D., \& Kirkpatrick, W. K. (2015). Creating a post-training evaluation plan. Training \& Development, 42 (I), I2.

Moldovan, L. (2016). Training Outcome Evaluation Model. Procedia Technology, 22, I I84-I I90. https://doi.org/I0.10I6/j.protcy.2016.01.I66

Paull, M., Whitsed, C., \& Girardi, A. (2016). Applying the Kirkpatrick model: Evaluating an "interaction for learning framework" curriculum intervention. Issues in Educational Research, 26(3), 490. 
Rafiq, M. (2015). Training Evaluation in an Organization using Kirkpatrick Model: A Case Study of PIA. Journal of Entrepreneurship \& Organization Management, O4(03). https://doi.org/I0.4172/2169-026X.I000I5I

Saunders, M. N. K., Lewis, P., \& Thornhill, A. (2015). Research methods for business students (Seventh edition). New York: Pearson Education.

Smidt, A., Balandin, S., Sigafoos, J., \& Reed, V. A. (2009). The Kirkpatrick model: A useful tool for evaluating training outcomes. Journal of Intellectual \& Developmental Disability, 34(3), 266-274. https://doi.org/I0.I080/I3668250903093125

\section{Copyrights}

Copyright for this article is retained by the author(s), with first publication rights granted to the journal. This is an open-access article distributed under the terms and conditions of the Creative Commons Attribution license (http://creativecommons.org/licenses/by/4.0/). 